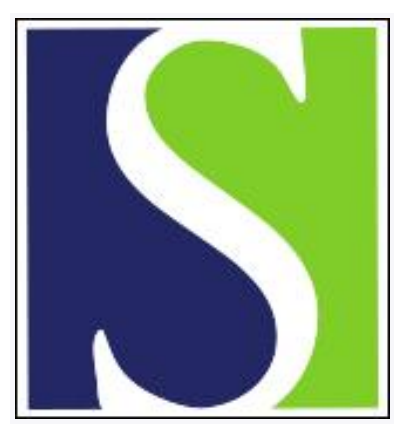

Scand J Work Environ Health 1999;25(5):385-386

https://doi.org/10.5271/sjweh.450

Issue date: Oct 1999

\title{
Work load and back pain
}

by Heliövaara M

This article in PubMed: www.ncbi.nlm.nih.gov/pubmed/10569457

\section{(c) (1)}




\section{Work load and back pain}

Back pain is a major cause of ill health and disability in affluent populations. To combat such a common ailment, observational epidemiologic studies are needed to identify high-risk groups and factors that determine the risk of back pain. Risk factors that may be amenable to change through intervention are potentially the most important. Most research has focused on work-related mechanical factors. During the past decade reviews on the role of such factors in relation to back pain have remained cautious or even nihilistic (1-4). In this issue of the Scandinavian Journal of Work, Environment \& Health, however, Hoogendoorn and her co-workers publish a systematic review concluding that there is strong evidence that manual materials handling, bending and twisting, and whole body vibration are risk factors for back pain (5). Progress seems also to have occurred in methods of assessing physical work exposures $(6,7)$.

So far, one of the main difficulties in epidemiologic studies is that the differentiation of back pain into etiologically different groups is both theoretically and practically probiematic. The paucity of diagnostic methods suitable for field work aggravates this problem in population surveys. The intermittent nature of back complaints is a further difficulty. Resolution without subsequent disability is common, and cross-sectional studies therefore miss a considerable proportion of cases. Retrospective assessments of back pain, usually depending on uncertain records or memory, are likely to result in bias, whereas prospective studies are costly and time-consuming.

A wealth of observational studies suggest that heavy manual work in general and frequent lifting, postural stress, and whole-body vibration in particular contribute not only to back pain (5) but also to degenerative changes of intervertebral discs and facet joints $(1,2,4)$ and to sciatica due to a herniated lumbar disc (1). From the view of work-related risk factors, therefore, Hoogendoorn and her co-workers could have included studies on herniated lumbar intervertebral discs in their review. The label of back pain inevitably comprises a multitude of conditions (including herniated discs), some or perhaps all with different etiology. Sciatica due to a herniated lumbar disc differs from other types of back pain in that specific investigations have been developed for its diagnosis. The results, in principle, provide a sufficient basis for epidemiologic research, or, at least, a more solid biomedical foundation than exists for other common types of low-back pain. There is some evidence of the importance of nonoccupational driving and lifting to sciatica due to a herniated lumbar disc $(1,8)$, unlike the situation for nonspecified back pain (5). Spinal stenosis could be another entity specific enough, but no study exists on its risk factors.

Epidemiologic studies focusing on the risk factors for sciatica due to herniated lumbar intervertebral disc suggest that driving a motor vehicle increases the risk (1). Associations found between driving and nonspecified back pain (5) appear weaker but rather consistent between studies. Whatever the outcome, however, whole-body vibration may not represent the crucial exposure because sudden starting and stopping, the transmission of road shocks, the lack of proper support for the back, and the position of the driver's legs simultaneously induce mechanical stresses on the lower back. Manual handling of materials and a lack of activities strengthening both musculature and connective tissues may also contribute to back complaints among occupational drivers. To distinguish between these factors will not be easy. Thus far, on the basis of epidemiologic evidence, it may be premature to conclude that wholebody vibration per se is a risk factor for back pain.

Insufficient control of confounding in previous studies may also hamper conclusions about the 
significance of manual materials handling and bending and twisting (5). Accident-related traumatic events, smoking, mental stress, tallness, overweight, and familiar aggregation (the combined effect of genes and shared early environment) are factors that predict an increased risk of back pain, and they can covary with physical work loads (1-4). Furthermore, unknown risk factors are likely to exist.

Physical load may also have prophylactic effects. As a result, strengthened muscles of the trunk and adaptation of the connective tissues can reduce sudden forces on the lower back that might otherwise damage spinal structures. Further research should seek to answer why physical activity at work exerts detrimental effects on the lower back, whereas physical activity during leisure rather seems to be prophylactic. The tangle probably could be undone by means of careful intervention studies and observational epidemiologic studies in which the interactions of work-related physical exposures $(6,7)$, physical activity during leisure, and muscular strength were adequately assessed for their prediction of back pain. The exposures may not be deleterious for everybody or in all circumstances.

In general, with regard to biological coherence, it seems difficult to make causal inference on the basis of occupation-related differences in the risk of back pain. One could consider it self-evident that back pain bothers especially those who need their backs for working. Back pain as a research topic has been treated as if it were an illness. It is, however, a complaint and, as such, is possibly not a genuine disease (9). Thus it cannot be concluded whether work load contributes to spinal injury, to aggravation of pain, or incapacity from it once an injury occurs, or to both. This problem for back pain research was realized over 30 years ago (10), but it is still topical today.

Whatever the mechanisms leading to differences in the risks between occupational groups, the primary prevention of back pain would have considerable potential if adequate tools could be developed. Various ergonomic measures and instructions on manual handling and lifting are widely believed to be prophylactic, although sufficient evidence is lacking that they are effective. However, if the association between work load and back pain is not due to back injury incidence but rather to a greater likelihood of symptoms and disability once an injury occurs, then primary prevention by ergonomic measures may prove elusive. The conclusions of Hoogendoorn and her co-workers (5) indicate the need for advanced epidemiologic studies, as well as intervention trials, in occupational medicine.

\section{References}

1. Heliövaara M. Risk factors for low back pain and sciatica. Ann Med 1989;21:257-64.

2. Riihimäki H. Back and limb disorders. In: McDonald C, editor. Epidemiology of work related diseases. London: BMJ Publishing Group, 1995.

3. Burdorf A, Sorock G. Positive and negative evidence of risk factors for back disorders. Scand J Work Environ Health $1997 ; 23: 243-56$

4. Videman T, Battié MC. The influence of occupation on lumbar degeneration. Spine 1999;24:1164-68.

5. Hoogendoorn WE, van Poppel MNM, Bongers PM, Koes BW, Bouter LM. Physical load during work and leisure time as risk factors for back pain [review]. Scand J Work Environ Health 1999;25(5):387-403.

6. Neumann WP, Wells RP, Norman RW, Andrews DM, Frank J, Shannon HS, et al. A comparison of four peak spinal loading exposure measurement methods and their association with low back pain. Scand J Work Environ Health $1999 ; 25(5): 404-9$.

7. Köster M, Alfredsson L, Michélsen H, Vingård E, Kilbom Å. Retrospective versus original information on physical and psychosocial exposure at work. Scand I Work Environ Health 1999;25(5):410-4.

8. Mundt DJ, Kelsey JL, Golden AL, et al. An epidemiologic study of non-occupational lifting as a risk factor for herniated lumbar intervertebral disc. Spine 1993;18:595-602.

9. Miettinen OS, Caro JJ. Medical research on a complaint: orientation and priorities. Ann Med 1989;21:399_401.

10. Troup JDG. Relation of lumbar spine disorders to heavy manual work and lifting. Lancet 1965;1:857-61.

\section{Markku Heliövaara \\ National Public Health Institute \\ Department of Health and Disability \\ Mannerheimintie 166 \\ FIN-00300 Helsinki Finland \\ [E-mail: markku.heliovaara@ktl.fi]}

